\title{
Gestão de desempenho por competência (GDP): análise da avaliação de desempenho para ascensão profissional utilizada em uma instituição bancária
}

\author{
Performance Management by Competence (GDP): performance \\ assessment analysis for career advancement used in a banking institution.
}

\author{
Samara Bolwerk ${ }^{1}$ \\ Giuliano Derrosso ${ }^{2}$ \\ Sinvales Roberto Souza ${ }^{3}$
}

1 Pós graduada em Gestão Estratégica de pessoas pelo Centro Universitário Dinâmica das Cataratas (UDC). Graduada em Administração e Turismo pela UNIOESTE. sbolwerk@hotmail.com

2 Mestre em Administração (UEM-PR), Graduado em Psicologia. Professor dos cursos de graduação e pós-graduação do Centro Universitário Dinâmica das Cataratas (UDC). giuliano@udc.edu.br

3 Mestre em Desenvolvimento Regional e Meio Ambiente, Economista. Coordenador Geral e docente do Centro Universitário Dinâmica das Cataratas (UDC).sinvales@udc.edu.br

\section{Resumo}

Cada vez mais, as empresas utilizam a área de Recursos Humanos para conseguir vantagem competitiva em relação a seus concorrentes. Devido a isso, elas estão implementando sistemas de avaliação de desempenho para, através dessas avaliações, poderem conhecer melhor as falhas de seus funcionários e sua necessidade de desenvolvimento, de forma que, com esses dados, possam investir no desenvolvimento profissional dos mesmos gerandosatisfação em seus colaboradores. Levando em consideração o papel cada vez mais importante das avaliações de desempenho nas organizações, o presente estudo faz uma análise geral da avaliação de desempenho utilizada por uma instituição financeira, a Gestão de Desempenho por Competências (GDP), e a sua forma de utilização, como um dos critérios para ascensão profissional dentro da empresa em estudo, buscando fazer uma comparação entre teoria e prática.

\section{Palavras-chave}

Gestão de Desempenho por Competências (GDP); avaliação de desempenho; desenvolvimento profissional.

\begin{abstract}
Increasingly companies are using the Human Resources area to achieve competitive edge over their competitors, due to that, they are implementing performance evaluation, that allow then to, through these ratings systems, know theweak spots of their employees and their needs for development, with such data, the firms, may invest in the professional development of the employees, thereby generating satisfaction among them. Considering the increasingly important role of performance evaluation in organizations, this study makes an overall analysis of performance evaluation used by a financial institution thePeople Management by Competency and its method of use, as one of the criteria for career advancement within the company under study, seeking to draw a comparison between theory and practice.
\end{abstract}

\section{Keywords}

People management by competency; performance evaluation; professional development.

\section{Como você deve citar?}

BOLWERK, Samara; DERROSSO, Giuliano; SOUZA, Sinvales Roberto. Gestão de desempenho por competência (GDP): análise da avaliação de desempenho para ascensão profissional utilizada em uma instituição bancária. Cadernos UniFOA, Volta Redonda, n. 26, p. 63-84, dez. 2014. 
Gestão de desempenho por competência (GDP): análise da avaliação de desempenho para ascensão profissional utilizada em uma instituição bancária

\section{INTRODUÇÃO}

Neste trabalho será apresentada a Gestão de Desempenho por Competência (GDP) e a forma como uma instituição bancária a utiliza, junto com diversos outros fatores, para promover a ascensão profissional dentro da empresa.

Nesse sentido, é importante frisar que a avaliação de desempenho, na empresa em questão, já é utilizada de forma clara para a promoção da ascensão profissional, algo que ainda não é muito comum nas organizações, já que, muitas vezes, mesmo as empresas que possuem sistemas implementados de avaliação de desempenho, não possuem uma utilização clara da mesma ou um processo de feedback.

O banco em estudo utiliza a GDP (Gestão de Desempenho por Competência) em uma avaliação, utilizando o Balanced Scorecard (BSC), e avaliação 360 graus, ou seja, todo funcionário é avaliado em cinco perspectivas básicas, que são: financeira, clientes, processos internos, comportamento organizacional e sociedade, sendo avaliado por seus superiores, pares (e subordinados, quando os tiver), além de realizar a autoavaliação. Nessa avaliação, os subordinados também avaliam seu superior.

Os ciclos de avaliação de desempenho são semestrais e ocorrem sempre no fechamento de cada semestre, para avaliação do desempenho do funcionário em todos os quesitos, inclusive no cumprimento de metas e na demonstração de competências específicas requeridas pelo banco.

Outro importante ponto a salientar é que o programa de ascensão profissional da instituição financeira em questão não é composto, apenas, pela avaliação de desempenho. Ela é uma parte do sistema de pontuação utilizado para classificação dos concorrentes nas concorrências internas. Os outros pontos considerados para ascensão profissional são: cursos realizados na universidade corporativa fornecidos pelo banco e cursos realizados fora do banco, graduação, pós-graduação, tempo de casa e a GDP. No entanto, no decorrer deste trabalho, o ponto a ser focado será a utilização da avaliação de desempenho.

Vale ressaltar que, apesar da empresa em estudo utilizar o processo de avaliação de desempenho para ascensão profissional, ainda possui muitas falhas no processo de fornecimento de feedback para os funcionários que passam pela avaliação, já que são poucas as vezes que são fornecidas explicações pelos avaliadores para notas mais baixas atribuídas aos funcionários avaliados.

Este estudo fará uma análise das referências teóricas sobre avaliação de desempenho e, especificamente, sobre a Gestão de Desempenho por Competência (GDP), fazendo uma comparação com o modelo já utilizado pelo banco, para responder à seguinte pergunta de pesquisa:

Como a Gestão de Desempenho por Competência (GDP) é utilizada em uma instituição bancária para avaliação de desempenho e consequente ascensão profissional?

O objetivo geral deste estudo é:

- Analisar como a Gestão de Desempenho por Competência (GDP) é utilizada em uma instituição bancária como avaliação de desempenho e como parte dos fatores para ascensão profissional.

Seguindo a linha do objetivo geral, os objetivos específicos a serem alcançados neste estudo são: 
1. Analisar os modelos teóricos de Gestão de Desempenho por Competência (GDP), relacionando a teoria com a prática utilizada em uma instituição bancária;

2. Descrever o sistema de Gestão de Desempenho por Competência (GDP) utilizado para avaliação de desempenho em uma instituição bancária;

3. Explicar a forma como o sistema de Gestão de Desempenho por Competência (GDP) é utilizado, como parte dos fatores, para promover a ascensão profissional, em uma instituição bancária.

Com este estudo, teremos a oportunidade de aprofundar o conhecimento na área de avaliação de desempenho, focando, principalmente, na Gestão de Desempenho por Competência (GDP) e sua utilização para a ascensão profissional, na instituição financeira em questão.

Neste trabalho, poderemos verificar como um sistema de avaliação de desempenho bem estruturado pode ajudar uma empresa a promover seus funcionários com base na meritocracia, de forma que $o$ bom trabalho e o esforço individual de cada um sejam reconhecidos no momento de nomeações internas.

Para a organização, a principal vantagem deste estudo é a realização de uma comparação entre a teoria e a prática realizada na empresa, ou seja, uma verificação entre os dados teóricos e as práticas da empresa, para que, dessa forma, exista a possibilidade de uma melhoria constante do sistema da avaliação de desempenho e, consequentemente, de seu sistema de ascensão profissional, por ser a avaliação de desempenho a questão mais subjetiva a ser levada em conta em seu programa de ascensão profissional.

Para a gestão em geral, este estudo será extremamente proveitoso, por apresentar para as empresas que já possuem uma avaliação de desempenho estabelecida, mas que não fazem uso dessa avaliação, uma forma de utilização de seus resultados, evitando dessa forma, que o processo avaliativo se torne "vazio" para os colaboradores da empresa.

\section{REVISÃO DE LITERATURA}

Neste capítulo, serão apresentados os principais conceitos referentes ao embasamento teórico relacionados ao tema proposto. Serão três temas principais: Gestão de Pessoas por Competência, Avaliação de Desempenho, Tipos de Avaliação de Desempenho com ênfase na Gestão de Desempenho por Competência (GDP), utilizada pela empresa em estudo.

\subsection{Gestão de Pessoas por Competência}

As empresas, cada vez mais, têm enfrentado desafios relacionadosà gestão de pessoas, e, a cada dia que passa, essa área se tornará mais decisiva para as empresas atingirem seus objetivos estratégicos.

É importante ressaltar que, para agregar valor à empresa e auxiliar no cumprimento de metas e objetivos operacionais, a área de gestão de pessoas precisa mudar e manter seu foco nos desafios estratégicos relacionados à gestão de pessoas, para, dessa forma, poder evoluir em conjunto com as demais áreas das empresas, ficando não somente focado na eficiência de atividades e processos (DUTRA, 2013). 
Gestão de desempenho por competência (GDP): análise da avaliação de desempenho para ascensão profissional utilizada em uma instituição bancária

Para suprir tal necessidade de desenvolvimento na área de gestão de pessoas, os profissionais da área estão utilizando diversas formas de inovação, sendo que uma das que mais tem sido utilizadas, atualmente, é a Gestão de Pessoas por Competência. Nesse sentido, para definirmos o que é Gestão de Pessoas por Competência é necessário apresentar uma definição das palavras "gestão" e "competência".

Gestão é o ato de administrar, gerir, planejar e liderar projetos, pessoas ou equipes em uma organização, ou seja, é o ato de organizar a empresa para que a mesma chegue a algum objetivo previamente traçado (MENDES, 2013).

Já competência está ligada aos três elementos conhecidos como CHA, ou seja, conhecimento, habilidades e atitudes. Conhecimento é adquirido com a formação educacional do indivíduo, é fundamentalmente teórico. Já a habilidade está ligada à prática, à aplicação do conhecimento no dia a dia de uma determinada atividade. A atitude é, basicamente, o comportamento humano, os valores e sentimentos das pessoas envolvidas (MENDES, 2013).

Figura 1 - As três dimensões da competência

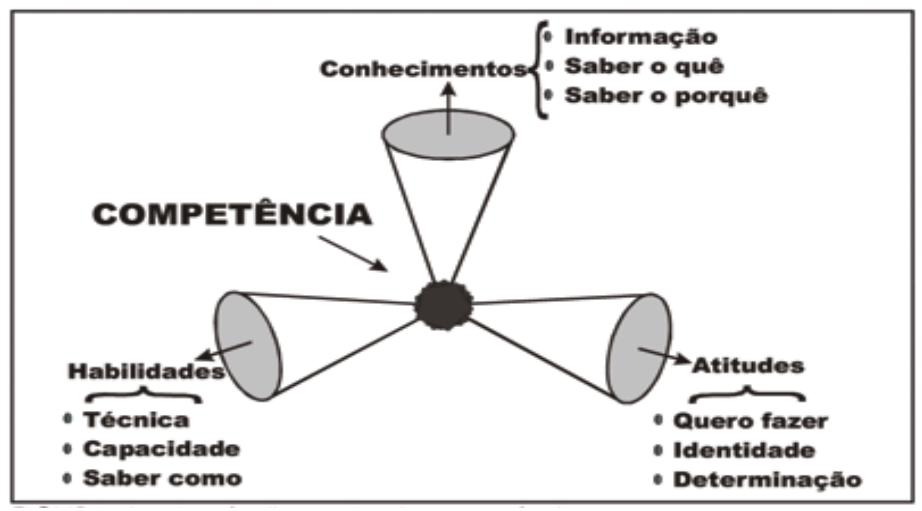

Fonte: Durand (2000) apud Brandão; Guimarães, 2001, p. 10.

A competência pode ser identificada na intersecção dos três elementos formadores, conforme apresentado na figura 1 .

Nesse cenário, com a necessidade de atualizar a gestão de desempenho, surge a Gestão de Pessoas por Competência. Nesse modelo de gestão, segundo Befort, Santos e Tadeucci (2012, p. 41), o gerenciamento por competência é o modelo de gestão que permite aos executivos terem uma visão mais
ampla acerca das competências exigidas para o exercício da função, ou seja, as competências de que uma
função precisa; que competências o colaborador possui e, posteriormente, fazer o cruzamento das informações
quanto às competências exigidas pela função versus competências do colaborador, para traçar um plano de
desenvolvimento especifico para cada colaborador, gerenciando os conhecimentos de forma eficiente e eficaz

Com esse modelo de gestão, os colaboradores devem ser capazes de identificar seus pontos fortes e fracos, suas habilidades e conhecimentos, para, dessa forma, oferecer à empresa as respostas corretas, principalmente, em relação a seu crescimento profissional e suas metas pessoais, buscando sempre a interseção entre os objetivos pessoais e os organizacionais.

É importante ressaltar que a gestão por competência tem, como um dos seus principais objetivos, ajudar os colaboradores das empresas a atingir o seu melhor desempenho profissional por meio do 
desenvolvimento das competências profissionais, buscando aumentar habilidades existentes e incluir novas. (BEFORT, SANTOS E TADEUCCI, 2012).

A gestão por competências deve ser realizada de forma sistematizada, para, dessa forma, poder definir perfis dos profissionais necessários a uma vaga específica, proporcionando maior produtividade do funcionário para o cargo em questão, buscando identificar os pontos de excelência do funcionário e os pontos de melhoria, a fim de suprir as lacunas de desenvolvimento profissional e agregando conhecimento, tendo, como base para tal, o desenvolvimento de critérios que possam ser mensurados (CHIAVENATO, 2006)

A gestão de pessoas por competência, no Brasil, tem sido adotada há pouco tempo, sendo um tema relativamente recente nas discussões e aplicações nas empresas. No entanto tem chamado a atenção dos profissionais da área de gestão de pessoas do país, já que, se o processo de gestão por competência for bem conduzido pelos profissionais responsáveis, pode gerar um aumento significativo nos negócios da empresa (PINTO, PEREIRA, COUTINHO E JOHANN, 2003).

Para que a gestão por competências seja bem aproveitada pelas empresas que utilizam esse método, as organizações devem traçar os resultados que desejam atingir, sempre pensando a longo prazo, adotando uma estratégia que seja coerente, para que, por meio dessa estratégia consiga identificar e desenvolver, em seus funcionários, as competências necessárias para atingir os propósitos previamente traçados pela organização (PINTO, PEREIRA, COUTINHO E JOHANN, 2003).

Vale ressaltar que, para que a empresa possa adotar a gestão de pessoas por competência, a organização deve identificar, de forma clara e objetiva, as lacunas de desenvolvimento de seus colaboradores, que possam impedir ou atrasar a realização dos objetivos organizacionais, para poder realizar os programas de desenvolvimento de forma eficiente e eficaz.

Em relação a essa questão, Pinto, Pereira, Coutinho e Johann (2003) acreditam que para acabar com essas deficiências dos funcionários em relação ao desempenho esperado pela organização, devem ser utilizados as diversas dimensões da gestão de pessoas, como, por exemplo, a captação e seleção de talentos, a remuneração e o reconhecimento, a educação continuada e a avaliação de desempenho.

Apenas saber quais as competências necessárias não é o suficiente para fazer com que a gestão de desempenho por competências seja corretamente implementada na empresa. É necessário fazer a avaliação do desempenho das competências exigidas dos funcionários no desempenho de suas funções, para que, dessa forma, possam ser feitas as adequações e melhorias entre o desempenho esperado dos colaboradores e o desempenho apresentado pelos mesmos.

\subsection{Avaliação de Desempenho}

Avaliar o desempenho dos colaboradores é vital para o crescimento da organização, pois evita que não estejam preparados e não apresentem um desempenho de acordo com o esperado pela organização e sejam recompensados com aumentos de salários e promoções, em detrimento dos colaboradores mais bem preparados e mais bem adaptados aos objetivos organizacionais (ARAUJO, 2006).

A avaliação de desempenho, para Chiavenatto (2004, p. 223), 
Gestão de desempenho por competência (GDP): análise da avaliação de desempenho para ascensão profissional utilizada em uma instituição bancária

é uma apreciação sistemática do desempenho de cada pessoa, em função das atividades que ela desempenha, das metas e resultados a serem alcançados e do seu potencial de desenvolvimento. A avaliação de desempenho é um processo que serve para julgar ou estimar o valor, a excelência e as qualidades de uma pessoa e, sobretudo, qual e a sua contribuição para o negócio da organização.

A atividade de avaliação de desempenho é um conjunto formado por um amplo processo, que começa na identificação do desempenho, seguindo para a mensuração do desempenho, alcançando, com essa medida, projeções de médio e longo prazo, construindo um mapa de onde o desempenho do colaborador tem maior potencial para colocar a serviço da organização (ARAUJO, 2006).

Vale lembrar que o próprio funcionário da organização espera que a mesma se posicione, através de seu gerente, em relação a seu desempenho profissional durante um determinado período de tempo (RIBEIRO, 2006). Essa avaliação, ainda segundo o autor, deve ser pelo menos anual, na data de aniversário da nomeação do colaborador para uma determinada função, para que ele possa acompanhar o seu desenvolvimento e tenha ciência de como seu trabalho tem sido percebido pela organização.

Para Chiavenato (2004), existem três razões principais para a realização da avaliação de desempenho nas organizações. São elas:

1. Com a realização da avaliação de desempenho, a organização pode fazer uma fundamentação sistemática de cada colaborador, utilizando esses dados em momento de necessidade, como, por exemplo, aumento de salário, promoções, transferências, e também de demissões de funcionários. Nesse sentido, com a avaliação de desempenho, a decisão dos gestores se torna fundamentada em dados e não apenas em perspectivas pessoais, que acabam fazendo com que os demais colaboradores se sintam injustiçados pela diretoria da empresa;

2. Aumentar o feedback dos funcionários, pois, pela realização de avaliação de desempenho constantes, pode-se mensurar a melhoria ou eventual piora do desempenho de um colaborador, podendo, dessa forma, sugerir ações de melhoria para desenvolvimento de competências ou até mudanças no $\mathrm{CHA}$ (comportamento, habilidade e atitude);

3. A realização da avaliação de desempenho traz uma maior transparência para o colaborador saber qual a impressão de seu gestor sobre seu trabalho, dando oportunidade para melhorias na comunicação entre as duas partes.

Para Araújo (2006), existem alguns cuidados que devem ser tomados em relação à aplicação de um processo de avaliação de desempenho. São eles:

1. O processo de avaliação de desempenho não deve estar ligado a desempenhos passados ou a acontecimentos recentes. Em relação ao desempenho do passado, os colaboradores não devem entender a avaliação de desempenho como uma gratificação ou uma punição para eventos anteriores, e sim como algo positivo que leve ao desenvolvimento futuro. Pensando da mesma forma, utilizar um acontecimento muito recente pode fazer com que apenas uma ação seja responsável pela avaliação do colaborador em um determinado período;

2. As ações burocráticas não devem ter ênfase maior do que a avaliação de desempenho. Nesse sentido, tal questão é bastante difícil, já que a maior ênfase nesse processo é, geralmente, a mensuração, perdendo a possibilidade de utilizar o processo como um catalisador para mudanças futuras; 
3. O processo não pode ser visto pelos avaliados como injusto ou como tendencioso, para não fazer com que o processo seja "vazio" para os colaboradores avaliados. Um ponto importante nessa questão é que os avaliadores devem ser bastante instruídos em relação a quais qualidades estão sendo avaliadas, para que não superavaliem um colaborador, devido a uma qualidade percebida que não é tão relevante para o cargo exercido pelo colaborador;

4. Deve-se ter grande cuidado para que os avaliadores tenham o mesmo grau de rigor para avaliar os colaboradores, pois graus muito diferentes de rigor podem gerar resultados que façam com que os colaboradores considerem todo o processo injusto. Outra importante questão é instruir os avaliadores a serem verdadeiros em relação aos avaliados, para não mascarar os resultados, tornando nulo o processo de avaliação;

5. A avaliação deve ser bem elaborada e estar sempre pautada em agregar valor aos envolvidos no processo. Da mesma forma, apresentar feedback sem pensar na forma correta de realizar o processo pode gerar descontentamento e uma atitude negativa, ao contrário do esperado com o processo de avaliação;

6. Outra questão importante é que o avaliador deve ser instruído a não nivelar as pessoas, ou seja, ele sempre deve levar em consideração que está avaliando pessoas diferentes, pois as necessidades de cada um devem ser exploradas no processo de avaliação de desempenho;

7. A avaliação de desempenho deve ser pensada de acordo com os objetivos da organização, ou seja, não deve ser simplesmente implementada. 0 processo deve ser pensado para se adaptar a organização.

A avaliação de desempenho pode trazer várias vantagens para a organização, ajudando a alcançar seus objetivos previamente traçados. A avaliação de desempenho ajuda a empresa a descobrir novos talentos, já que ajuda a identificar os principais atributos dos colaboradores. Facilita o feedback para as pessoas, já que os resultados da avaliação são palpáveis e mensuráveis, podendo ser expostos aos avaliados. Ajuda a situar as pessoas em relação à organização, seus objetivos, e ajuda a integrar os objetivos pessoais aos objetivos organizacionais. Outro ponto importante da avaliação de desempenho e que ela incentiva a utilização do coaching, ou seja, uma ação de aconselhamento individualizado, para que cada colaborador possa desenvolver todo o seu potencial, para auxiliar a organização (ARAUJO, 2006).

Nesse sentido, vale ressaltar, que, apesar de a avaliação de desempenho ter vários pontos positivos e trazer diversas vantagens às organizações, existem também algumas limitações como, por exemplo, tratar-se de um processo vulnerável, já que é um processo bastante subjetivo. Outra questão importante é que existe uma grande dificuldade em manter as avaliações periódicas, já que as avaliações de desempenho dependem fundamentalmente do fornecimento de feedback dos avaliadores para os avaliados, mas, na maioria das organizações, não existe nenhum sistema que sistematize talfeedback, o que acaba atrapalhando a realização da avaliação de desempenho, devido à correria do dia a dia das organizações (ARAUJO, 2006).

Ainda para Araujo (2006), para garantir que o processo seja bem realizado, alguns pré-requisitos devem ser cumpridos, antes da realização da avaliação de desempenho, para a efetividade do projeto no futuro da organização. Os pré-requisitos citados pelo autor são:

1. O objetivo deve estar claramente em sintonia com o desempenho esperado, pois, quando o objetivo é bem definido e coordenado com o desempenho esperado dos colaboradores, fará com que o desenvolvimento dos mesmos seja mais natural, facilitando o processo; 
Gestão de desempenho por competência (GDP): análise da avaliação de desempenho para ascensão profissional utilizada em uma instituição bancária

2. Outra questão importante é determinar quem será o responsável pelo processo de avaliação de desempenho. Uma pessoa deve se responsabilizar pela aplicação e pelos procedimentos;

3. Deve haver concordância de quem avalia e de quem e avaliado, já que, ao aceitar passar por um processo de avaliação, o colaborador deve saber que está aceitando um processo que acarretará mudanças no futuro e, devido a isso, o consentimento e extremamente importante para que o fluxo ocorra corretamente.

De acordo com Chiavenato (2004, p. 227),

a avaliação de desempenho é um processo de redução da incerteza e, ao mesmo tempo, de busca de consonância. A avaliação reduz a incerteza do funcionário ao proporcionar retroação a respeito do seu desempenho. Ela busca a consonância na medida em que proporciona a troca de ideias e concordância de conceitos entre funcionário e seu gerente. Na realidade, a avaliação do desempenho deve mostrar ao funcionário o que as pessoas pensam a respeito de seu trabalho e da sua contribuição ao organização e ao cliente.

Chiavenato (2004) também registra que as empresas utilizam as mais diferentes alternativas em relação a quem realiza a avaliação de desempenho. Segundo ele, as fontes mais comuns de avaliação são: Autoavaliação, o gerente, o indivíduo e o gerente, a equipe de trabalho, a avaliação para cima, a comissão de avaliação de desempenho e o órgão de RH. Os conceitos apresentados a partir de agora são todos baseados na obra de Chiavenato (2004).

A autoavaliação é utilizada por empresas mais democráticas. Para o autor, o ideal das avaliações seria se todo funcionário avaliasse sua própria competência no desenvolvimento do trabalho, utilizando critérios pré-estabelecidos, para que a subjetividade do processo seja diminuída. 0 próprio indivíduo acompanha suas necessidades de treinamento e desenvolvimento, para atingir os objetivos pessoais e corporativos.

A forma mais utilizada pelas organizações para avaliação de desempenho é a avaliação realizada pelo gerente, ou seja, o gestor direto do colaborador,que faz a avaliação de desempenho com a ajuda do órgão do Recursos Humanos, para elaboração do processo de avaliação.

Outro método utilizado é o que o gerente e o indivíduosão responsáveis pela avaliação: o indivíduo faz a avaliação propriamente dita e o gerente trabalha na orientação do colaborador, fornecendo os recursos necessários para o crescimento e desenvolvimento das competências avaliadas.

A avaliação pode ser feita também por uma equipe de trabalho, ou seja, a própria equipe traça suas metas e objetivos e faz a avaliação do desempenho dos integrantes do grupo.

A avaliação para cima é a avaliação feita pelos colaboradores da equipe sobre seu gestor, ou seja, a equipe avalia como o gestor está ajudando os funcionários a desenvolverem suas competências, ou seja, sua efetividade como gestor.

A comissão de avaliação do desempenho é formada por um grupo de funcionários das mais diversas áreas da organização, que podem, ou não, ter interesse pessoal na avaliação de um determinado funcionário. Essas comissões são formadas por membros fixos e transitórios.

A forma mais antiga, e que está cada vez mais caindo em desuso pelas organizações, é a avaliação de desempenho realizada pelo órgão de Recursos Humanos, ou seja, o órgão de recursos humanos centraliza todo o processo burocrático da avaliação, solicitando aos gerentes diretos dos avaliados 
as impressões deles em relação ao colaborador para realizar a avaliação de desempenho. Com essas impressões, são preenchidos relatórios que se tornam a avaliação de desempenho do colaborador.

Para Chiavenato (2004, p. 230),

[...] avaliar o desempenho de um grande número de pessoas dentro das organizações utilizando critérios de equidade e de justiça, e, ao mesmo tempo, estimulando as pessoas, não é tarefa fácil. Por esta razão, muitas organizações constroem seus próprios sistemas de avaliação ajustados as características peculiares do seu pessoal. É comum o desdobramento desses sistemas de avaliação em pessoal de direção e gerencia (predominando a visão estratégica), mensalistas (predominando a visão tática) e horistas (predominando a visão operacional).

Vale ressaltar que as avaliações de desempenho são realizadas das mais diversas formas, no entanto, apesar das diversas opções, para escolher uma para a organização é necessário que se faça um estudo para verificar qual método se encaixa melhor nas necessidades e objetivos da empresa.

\subsection{Tipos de avaliação de desempenho}

A seguir serão apresentados alguns dos principais métodos de avaliação de desempenho na visão de Chiavenato (2004) e Araujo (2006).

Escalas gráficas: é um método pelo qual uma tabela com duas entradas é utilizada para realizar a avaliação. A tabela tem, nas suas linhas, os fatores de avaliação e, nas colunas, os graus de avaliação de desempenho (CHIAVENATO, 2004).

Os fatores de avaliação devem ser bem escolhidos pela organização, lembrando sempre que devem agregar valor ao processo, ou seja, os fatores escolhidos devem ser valorizados em todos os cargos da organização. Nesse método, as pessoas são avaliadas de acordo com fatores previamente definidos e graduados. Cada fator deve ser definido com uma descrição simples e bastante objetiva do que será avaliado, quanto mais bem definido o fator, melhor será a mensuração que ele trará.

Para Chiavenato (2004), "cada fator é dimensionado para retratar uma gama ampla de desempenho: desde o desempenho fraco ou insatisfatório, até um desempenho ótimo ou excelente. Entre os extremos, existem várias alternativas intermediárias".

Após definidos os fatores de avaliação, o autor afırma que o próximo passo é definir quais serão os graus de avaliação para depois definir qual será a escala de variação. Geralmente, nas escalas gráficas, são utilizados de três a cinco graus de variação (ótimo, bom, regular, sofrível e fraco). Depois de definidos os fatores e as escalas gráficas, monta-se a avaliação propriamente dita (CHIAVENATO, 2004). 
Gestão de desempenho por competência (GDP): análise da avaliação de desempenho para ascensão profissional utilizada em uma instituição bancária

Figura 2 - Avaliação de desempenho por escala gráfica

Escala Grafica

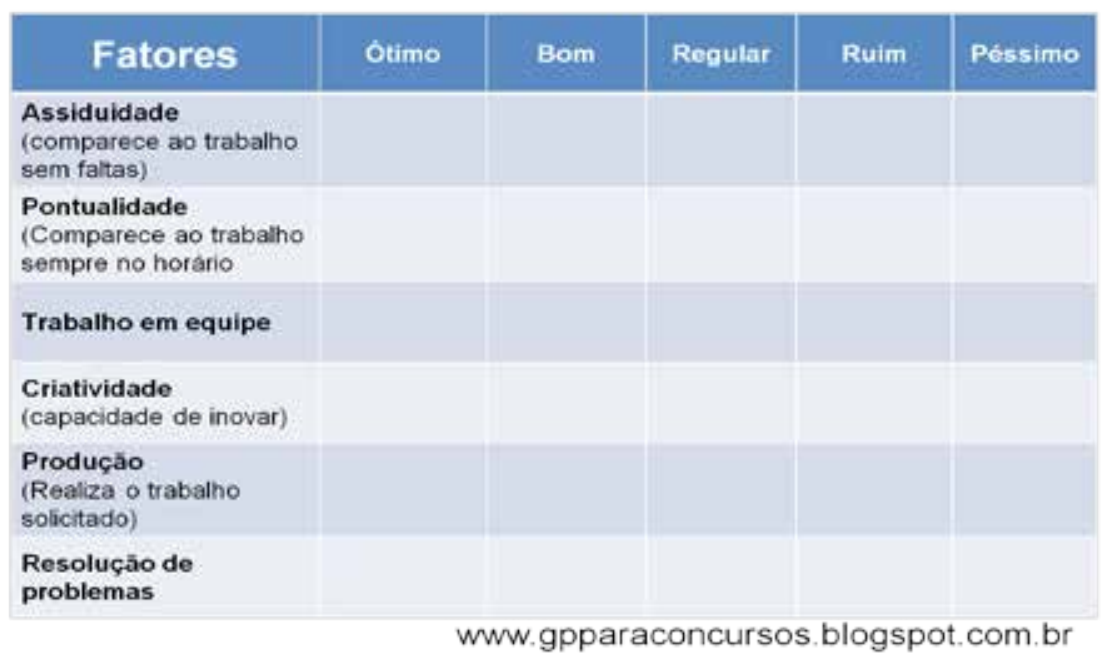

Fonte: RIBAS e SALIM (2012) - GP Concursos

Escolha forçada: Esse método minimiza as subjetividades do processo de avaliação (ARAUJO, 2006).

Nessa avaliação, o desempenho dos colaboradores é medido através de blocos que contêm frases descritivascom objetivo de focar algum determinado aspecto do comportamento humano. Cada bloco contém entre duas e quatro frases e o avaliador precisa escolher apenas uma das alternativas para identificar o desempenho do funcionário avaliado.

Figura 3 - Avaliação de desempenho por escolha forçada

\begin{tabular}{|c|c|c|c|}
\hline \multicolumn{4}{|c|}{ Departamento/Seleçふo: ____ Data:__l__ } \\
\hline & $\mathrm{N}=$ & + & $=$ \\
\hline Érapido no desempenho de suas tarefas & 2 & & \\
\hline Cdescortés com os colegas & $\hat{z}$ & & \\
\hline Conhece bem seu trabalino & 3 & & \\
\hline Năo merece murta contiança & 4 & & \\
\hline Todos os colegas gostam dele & 5 & & \\
\hline Costuma reclamar do serviço & 6 & & \\
\hline Tem um bom potencial de trabaltho & $\frac{\pi}{2}$ & & \\
\hline Edinamico & s & & \\
\hline Cuida bem de seu material de trabalho & 9 & & \\
\hline Ceriterioso na tomada de decisర̃es & 10 & & \\
\hline So fax o que the mandarm & 11 & & \\
\hline Seu comportamento e irrepreensivel & 12 & & \\
\hline Aceita de bom grado as sugestōes & 41 & & \\
\hline Näo culda de sua aparencia & 42 & & \\
\hline Tem facilidade de expressăo & 43 & & \\
\hline Nä̌o procura se atualizar & 44 & & \\
\hline É simpótico & 45 & & \\
\hline Temmedo de pedir ajuda & 46 & & \\
\hline Preocupa-se com a produtividade & 47 & & \\
\hline Costuma agredir os colegas & 48 & & \\
\hline Está bem integrado ao grupo & & & \\
\hline Costuma desperdiçar material & so & & \\
\hline Edisciplinado & 51 & & \\
\hline Tempoura iniciativa & 52 & & \\
\hline
\end{tabular}

Fonte: LUCIA (2011) - Assessoria Conrado - Cursos Treinamentos \& Consultoria

Pesquisa de campo: É um dos métodos tradicionais mais completos de avaliação de desempenho. Nessa forma de avaliação, é necessário que um especialista nos métodos de avaliação faça uma entrevista com os gerentes, para, em conjunto, avaliar os colaboradores (CHIAVENATO, 2004). 
Com as entrevistas realizadas, o especialista preenche um formulário de avaliação sobre cada um dos colaboradores avaliados. São quatro as etapas do processo: entrevista para uma avaliação inicial, entrevista para análise complementar, planejamento das providências e acompanhamento dos resultados.

Método de incidentes críticos: nessa avaliação existe uma ideia bastante simplista em que o foco da avaliação é os pontos fracos e fortes do avaliado. São avaliados os traços das pessoas em atitudes extremas, sem levar em conta traços de personalidade (ARAUJO, 2006).

Os incidentes críticos, ainda segundo o autor, devem ser anotados, no mínimo, semanalmente. Esse tipo de avaliação, geralmente, apresenta resultados ou altamente satisfatórios ou muito insatisfatórios (CHIAVENATO, 2004).

Figura 4 - Avaliação de desempenho por Incidentes Críticos

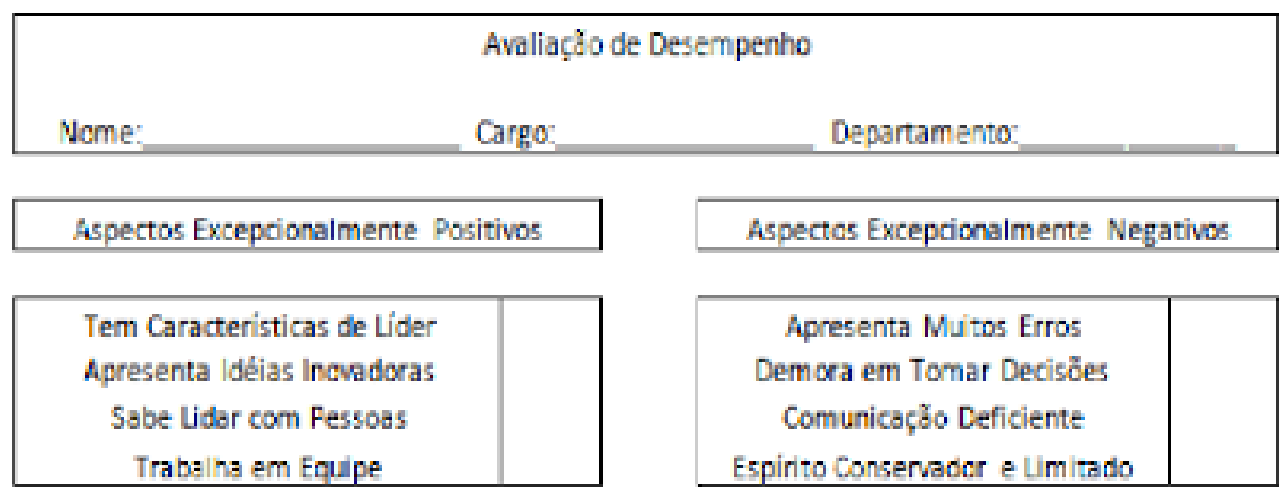

Fonte: G. T. H Consultoria em RH (2011)

Listas de verificação: essa forma de avaliação ainda é bastante tradicional,sendo utilizada até hoje pelas organizações, já que as empresas buscam avaliar os colaboradores com base em fatores individuais (ARAUJO, 2006).

A lista de verificação serve como um checklist, para que o gestor responsável pela avaliação se lembre de avaliar somente as competências essenciais dos avaliados. Nesse caso, o avaliador marca apenas as competências que ele acredita que o avaliado possua, não marcando nada nas que ele não acredita que $o$ avaliado apresente.

Avaliação por escrito: essa forma de avaliação se assemelha à avaliação por incidentes críticos, mas, ao contrário, a avaliação por escrito é mais aprofundada (ARAUJO, 2006).

Nesse modo de avaliação, o avaliador tem a oportunidade de dar ênfase a algumas características que considera importante sobre o avaliado, desde que seja adequado aos objetivos da avaliação, ou seja, aos comportamentos e competências previamente discutidos.

Na avaliação escrita, a maior dificuldade é a diferença de tamanho entre as avaliações dos colaboradores, mas não deve ser coibido, pois, muitas vezes, ao padronizar o tamanho das avaliações se perdem informações importantes. 
Gestão de desempenho por competência (GDP): análise da avaliação de desempenho para ascensão profissional utilizada em uma instituição bancária

Método Comparativo: nesse método, é realizada uma comparação entre duas pessoas da organização ou entre uma pessoa e um determinado grupo. Tal comparação serve, principalmente, para gerar um padrão de comportamento esperado para um determinado cargo da organização (ARAUJO, 2006).

Padrões de Trabalho: o método por padrões de trabalho é uma alternativa em relação ao método comparativo de avaliação de desempenho, poisconsiste na própria empresa estabelecer métodos e objetivos a serem alcançados em um determinado período de tempo, sendo que, esses padrões podem ser estabelecidos pelo método comparativo. Nessa avaliação, é de suma importância que todos os avaliados saibam dos métodos e padrões de avaliação (ARAUJO, 2006).

Avaliação por Objetivos (APO): essa forma de avaliação é realizada através da fixação de metas pelos avaliados e pelos avaliadores, metas estas, que devem estar em consonância com os objetivos da organização (ARAUJO, 2006).

Nesse sentido, é necessário tomar cuidado para não restringir a criatividade e a vontade dos funcionários de atingir o padrão de excelência, pois, muitas vezes, quando atinge o nível satisfatório o colaborador, tende a estagnar, não buscando seu melhor desempenho.

Avaliação 360 graus: Na avaliação em 360 graus, todos os envolvidos devem participar do processo de avaliação, ou seja, todos que interagem com o avaliado devem fazer a avaliação, podemos citar o gerente, pares, subordinados, clientes (tanto internos quanto externos) e fornecedores (ARAUJO, 2006).

Essa avaliação é muito interessante, já que revela os mais diversos pontos de vista em relação ao avaliado. No entanto, essa forma de avaliação pode fazer com que o avaliado se sinta exposto, 0 que pode ser bom ou ruim. Bom, no sentido de que a pessoa avaliada pode ter ganhos em relação à avaliação, criando uma zona de conforto para o funcionário. E ruim, no sentido de o avaliado não estar preparado, na questão emocional, para receber críticas em relação a seu trabalho, gerando uma dificuldade em relação ao crescimento do colaborador dentro da organização.

Figura 5 - Avaliação de desempenho 360 graus

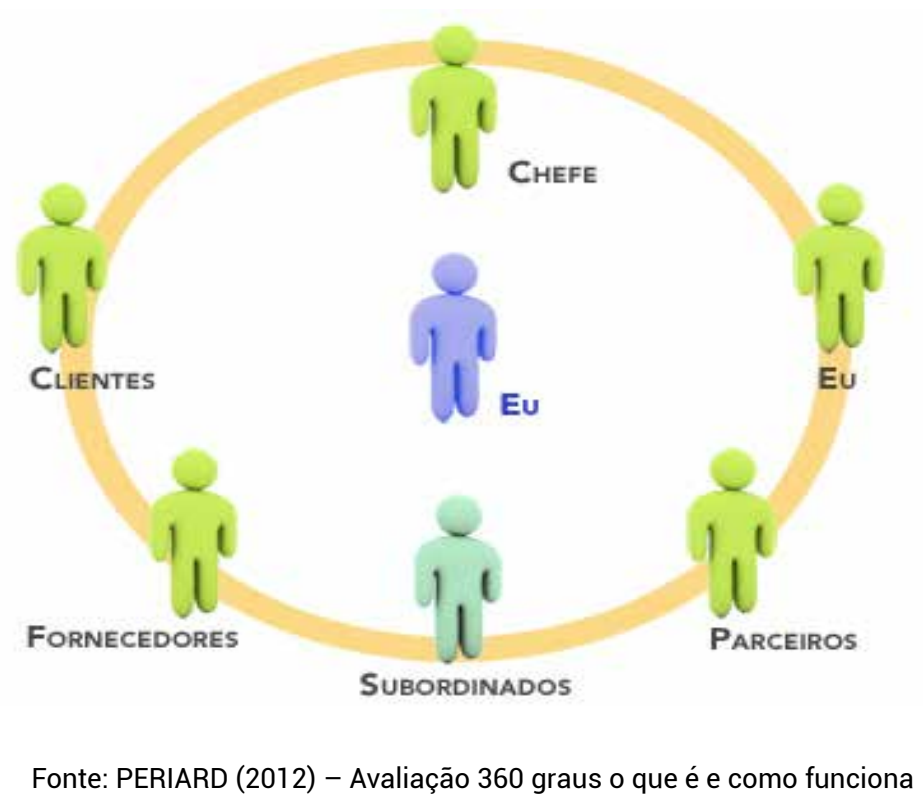


Balanced Scorecard (BSC): esse sistema que, hoje, é utilizado como uma gestão em longo prazo, surgiu como uma forma de avaliação de desempenho. Nele, o colaborador é avaliado em relação a quatro perspectivas: a financeira, do cliente, dos processos internos e do aprendizado e crescimento. Esse método é um contraponto dos métodos tradicionais de avaliação, já que foca quatro perspectivas complementares e não apenas a perspectiva financeira (ARAUJO, 2006).

Araujo (2006) afirma, ainda, que nessa avaliação são definidas tarefas que ajudam no alcance da meta para cada um dos objetivos estratégicos previamente traçados, de modo que, caso esses objetivos não sejam alcançados, as tarefas são reformadas, portanto, nessa forma de avaliação, é o objetivo estratégico que serve como um alicerce para a definição das metas, e as ações que serão realizadas para que as metas sejam devidamente alcançadas são as que poderão ser substituídas, no caso de as metas não serem atingidas e, consequentemente, os objetivos nãos sejam cumpridos.

Uma das principais vantagens desse método, ainda, segundo Araujo (2006), é a possibilidade de criar procedimentos e não apenas avaliá-los. Além disso, devido à relação de causa e efeito entre os objetivos estratégicos, as tarefas e as metas da empresa, ela faz com que a empresa não tenha a crença de que a organização possui alguma vantagem competitiva que vá durar para sempre, buscando, dessa forma, um foco na melhoria contínua.

Figura 6 - Balanced Scorecard (BSC)

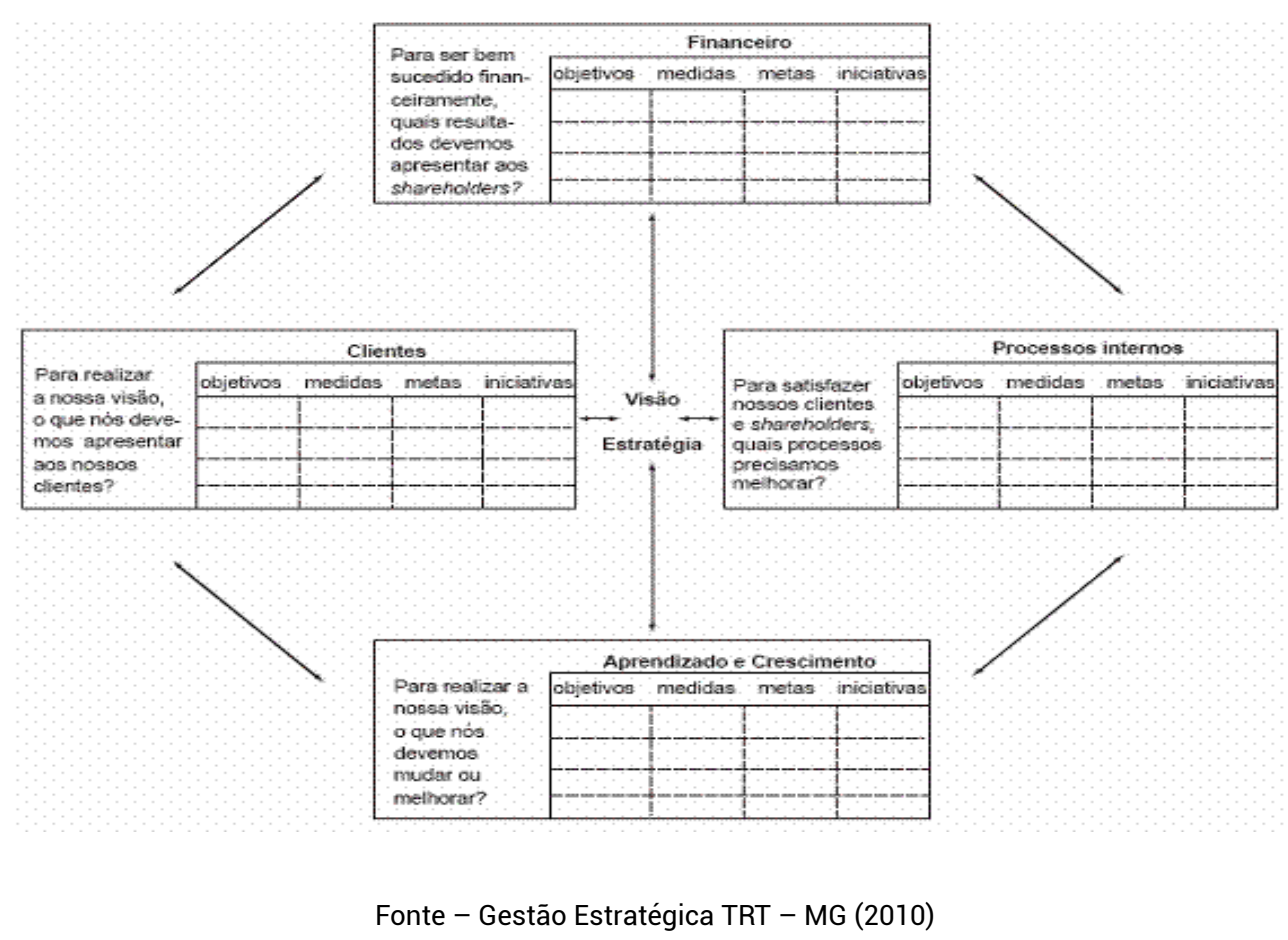

Gestão de Desempenho por Competência: Para Almeida (2007, p. 29), nesse sistema de avaliação, "odesempenho profissional é mensurado pelas competências expressas pelo funcionário no trabalho e pelos resultados, consecução das metas, decorrentes da expressão de competências profissionais [...]" 
Gestão de desempenho por competência (GDP): análise da avaliação de desempenho para ascensão profissional utilizada em uma instituição bancária

Ainda, segundo a autora, tem os seguintes objetivos principais:

1. Fazer com que as relações de trabalho sejam mais democráticas;

2. Orientar o processo de desenvolvimento pessoal, contribuindo para o desenvolvimento da carreira do colaborador, tendo sempre em mente as metas e objetivos da empresa;

3. Sistematizar as informações para que o gerenciamento do desempenho dos colaboradores seja disponibilizado, tanto para o colaborador quanto para os gestores, de forma que o desempenho do colaborador seja vinculado aos objetivos da empresa.

É importante ressaltar que o sistema de gestão de desempenho deve sempre ter como objetivo principal contribuir para que a empresa possa cumprir sua missão e atingir os objetivos estratégicos previamente traçados pela mesma.

Nesse tipo de avaliação de desempenho, a exigência de competências a ser apresentada por cada funcionário deve ser proporcional ao cargo exercido pelo avaliado, sendo que, a cada cargo exercido,são acrescentadas algumas competências do funcionário.Dessa forma, a empresa tem como ajudá-lo a desenvolver as competências necessárias para atingir o próximo nível hierárquico da organização, colaborando para os objetivos organizacionais e pessoais (ALMEIDA, 2007).

Ainda, segundo Almeida (2007), a avaliação na forma da gestão de desempenho por competência, é, na verdade, uma mistura entre a avaliação feita pelo BSC e pela avaliação 360 graus, além, é claro, da avaliação realizada do nível de competência apresentada por cada um dos funcionários em sua função, lembrando que as competências a serem avaliadas devem ser previamente acordadas entre avaliadores e avaliados, de forma que agreguem valor ao processo. Conforme Almeida (2007, p. 30), o referido processo "considera que o desempenho do funcionário é constituído por suas competências e pelos resultados gerados com a aplicação dessas competências em sua atuação profissional"

Nesse sentido, deve-se levar em conta que, assim como o modelo BSC, a gestão de desempenho por competência é focada nas quatro perspectivas básicas do BSC, ou seja, financeira, do cliente, dos processos internos e do aprendizado e crescimento. Medir todas essas perspectivas faz com que a empresa busque o equilíbrio entre as ações organizacionais e as ações voltadas para a comunidade, buscando sempre o equilíbrio socioambiental.

Essas perspectivas de avaliação são mensuradas em duas frentes, o cumprimento de metas e competências demonstradas. As metas são mensuradas de acordo com o cumprimento das mesmas acordadas no início do processo de avaliação. Já na questão de competências, elas são medidas de acordo com competências previamente definidas para um determinado cargo, e a forma como o avaliado demonstrou essas competências durante o período de avaliação (ALMEIDA, 2007).

Vale ressaltar que, apesar de todas as formas de avaliação de desempenho terem sido apresentadas individualmente, elas, muitas vezes, são usadas de forma complementar dentro das empresas, já que, para muitas delas, utilizar apenas uma forma não abrangeria sua complexidade organizacional.

\section{METODOLOGIA}

O método é a forma pela qual se busca atingir um determinado objetivo de pesquisa, conforme preceitua Richardson (1999, p. 22). 0 autor cita que metodologia são"procedimentos e regras utilizadas 
por determinado método". Dessa forma, neste capítulo, serão apresentados os procedimentos metodológicos que serão utilizados no decorrer deste artigo cientifico.

\title{
4.1 Tipologia e métodos de pesquisa
}

Tendo em vista o objetivo geral deste artigo, que é Analisar como a Avaliação de Desempenho por Competência (GDP) é utilizada em uma instituição bancária como avaliação de desempenho e para ascensão profissional, a pesquisa será realizada de forma predominantemente qualitativa, que, para Leopardi $(2001$, p. 28), ocorre "quando o interesse não está focalizado em contar o número de vezes em que uma variável aparece, mas sim, que qualidade elas apresentam".

\subsubsection{Técnica de coleta de dados}

Para a realização deste trabalho serão realizadas pesquisas bibliográficas, em fontes secundárias, que foram buscadas em livros de diversos autores preeminentes no assunto a ser estudado, além de referências eletrônicasde artigos e revistas publicados sobre o objeto em pauta.

Além das pesquisas bibliográficas, será utilizada, também, outra forma de coleta de dados para a realização deste estudo: pesquisa documental realizada em instruções normativas da empresa em estudo sobre a avaliação de desempenho, cursos institucionais ministrados aos funcionários recém-admitidos sobre a avaliação de desempenho e cursos disponibilizados na universidade corporativa sobre $o$ assunto.

Para Gil (2008), a pesquisa documental é similar à pesquisa bibliográfıca. A principal diferença é a natureza das fontes de estudo, já que a pesquisa documental, ao contrário da pesquisa bibliográfica, utiliza materiais que ainda não foram analisados e que podem, ainda, ser reeditados, levando em consideração os objetivos da pesquisa. Além de fazer a primeira análise de alguns documentos, a pesquisa documental pode ainda trazer uma nova interpretação da analises já existentes, o que pode acontecer com relatórios de empresa, tabelas, entre outros.

Para a realização do estudo serão aplicados os dois métodos de pesquisa, de forma a fazer uma comparação com o modelo utilizado na empresa em estudo e o modelo teórico de avaliação de desempenho.

\subsubsection{INSTRUMENTOS DE ANALISE}

A análise dos dados se dará por meio da análise de conteúdo. Segundo Moraes (1999, p 7-32),

\begin{abstract}
a análise de conteúdo constitui uma metodologia de pesquisa usada para descrever e interpretar o conteúdo de toda classe de documentos e textos. Essa análise, conduzindo a descrições sistemáticas, qualitativas ou quantitativas, ajuda a reinterpretar as mensagens e a atingir uma compreensão de seus significados num nível que vai além de uma leitura comum.
\end{abstract}

O conteúdo a ser analisado será o obtido por meio da pesquisa bibliográfica e da pesquisa documental.

A análise se dará pela comparação entre os métodos encontrados nas pesquisas teóricas com as práticas encontradas na instituição financeira estudada. Essa análise comparativa terá por objetivo verificar se o que é feito na empresa está de acordo com os preceitos teóricos, e quais os principais pontos de melhoria que podem ser implementados pela empresa para melhor utilização de seu sistema de avaliação de desempenho. 
Gestão de desempenho por competência (GDP): análise da avaliação de desempenho para ascensão profissional utilizada em uma instituição bancária

\section{ANÁLISE DE DADOS}

Neste capitulo, serão apresentados os resultados encontrados nas pesquisas bibliográficas e documentais por meio da comparação entre as duas formas de pesquisa, ou seja, o que vem sendo aplicado na instituição financeira estudada e o que preceitua a teoria sobre o assunto.

\subsection{Gestão de pessoas por competência e avaliação de desempenho}

A gestão de pessoas por competência é, cada vez mais, uma tendência para o setor de Recursos Humanos da organização. Desenvolver pessoas, através do desenvolvimento do CHA (Conhecimento, habilidades e atitudes), é, talvez, a maior inovação da área de gestão de pessoas dos últimos tempos.

Entretanto, não adianta apenas desenvolver qualquer aspecto do colaborador, pois o aspecto desenvolvido deve ser o que a empresa mais precisa para o bom desenvolvimento dos objetivos organizacionais, de forma que o colaborador possa fazer o seu melhor para atingir as metas previamente traçadas pela empresa. Nesse sentido, vale ressaltar que a empresa deve fazer um levantamento das competências que precisam de aprimoramento em seus colaboradores, para que o treinamento seja eficiente e eficaz para melhorar o empregado para atingir os objetivos da organização.

Uma questão bastante importante em relação à gestão de pessoas por competências é que não adianta apenas tentar aprimorar as competências dos colaboradores sem ter um sistema de avaliação que possa verificar a melhoria dessas competências nas atribuições dos mesmos. A avaliação de desempenho deve verificar as necessidades de melhoria e, após serem tomadas ações para seu desenvolvimento, verificar a melhoria do aspecto aperfeiçoado. Deve verificar a diferença entre a competência que o colaborador apresenta e o que a organização espera dele e, após análiseda diferença, devem ser traçadas ações que busquem equilibrar esses dois aspectos.

Noutra visão, é importante lembrar que existem diversas formas de realizar avaliações de desempenho. A empresa que deseja implementar a avaliação, deve estudar as formas de avaliaçãopara, assim, aplicar a que mais se adapte a ela, buscando sempre o melhor entendimento da organização e da necessidade de seus funcionários.

\subsection{Descrição e comparaçao com modelos teóricos da avaliação utilizada pela empresa em estudo}

A instituição financeira em estudo utiliza a avaliação de desempenho por competência (GDP) como forma de avaliação de seus colaboradores. As avaliações de desempenho são realizadas semestralmente (janeiro a junho e de julho a dezembro), e cada funcionário e avaliado por seu superior, seus pares, e seus subordinados (caso os possua), a além de realizar a autoavaliação.

Os resultados apresentados pelos colaboradores são medidos de duas formas fundamentais: as competências apresentadas por ele durante o período de avaliação e os resultados que a aplicação dessas competências geram para a organização. Os colaboradores da empresa são avaliados em cinco perspectivas básicas, que são: financeira, clientes, processos internos, comportamento organizacional e sociedade.

Essas cinco perspectivas são medidas, levando em consideração duas premissas básicas: metas são avaliadas diretamente pelo sistema da empresa, que define a nota da avaliação, a partir do atingimento delas, previamente acordadas no acordo de trabalho. A outra premissa são as competências que medem a forma como o $\mathrm{CHA}$ (conhecimento, habilidades e atitudes) é utilizado durante o período de avaliação para ajudar a organização a cumprir seus objetivos estratégicos. 
A avaliação é feita com notas que vão de 1 a 7 , de acordo com a forma como a competência é apresentada durante o ciclo de avaliação, sendo que 1,2 e 3 são consideradas notas muito abaixo do esperado; a nota 4 está um pouco abaixo do esperado; a 5 é a média esperada; nota 6 é um pouco acima do esperado; enquanto 7 é atribuída quando a competência foi apresentada de forma muito acima do esperado pela empresa. Vale ressaltar que, para poder dar uma nota negativa (1, 2 e 3), é necessário que o avaliador faça anotações no sistema que realiza a gestãoda avaliação de desempenho, sobre a competência a ser avaliada, e o que o avaliado está fazendo de errado, para que o mesmo possa acessar essas informações e tentar corrigir seus erros, antes do fechamento do sistema de avaliação.

Em relação às notas das avaliações, quando o avaliado recebe, na média dos avaliadores, uma nota igual ou inferior a 4,5 pontos, ele é contatado pela área de gestão de pessoas da empresa, para que realize um Plano de Desenvolvimento por Competência. Nesse plano, ele deve escolher até três cursos, que podem ser presenciais ou online, realizados na universidade corporativa da empresa em estudo. Esses cursos são realizados com o intuito de desenvolver a competência que teve a nota abaixo do esperado na avaliação.

Na instituição financeira em estudo, o processo de avaliação é realizado em três etapas: planejamento, acompanhamento e encerramento. A etapa do planejamento ocorre junto com o encerramento do período de avaliação anterior, quando são selecionados quem serão os avaliadores de cada um dos funcionários. 0 gerente escolhe seus avaliados e o sistema escolhe o restante dos integrantes do grupo avaliador. Nesse período, também é feito o acordo de equipe, no qual cada um dos avaliados é instruído sobre como será avaliado, e qual serão as competências avaliadas no período. Nessa etapa, também é realizado o acordo do trabalho, que é um plano maior, feito para todas as dependências do banco em questão. É no acordo de trabalho que o sistema faz a avaliação do cumprimento das metas para complementar a avaliação de desempenho.

Já a fase de acompanhamento ocorre durante todo o período de avaliação. É nessa fase que anotações devem ser feitas no sistema de acompanhamento de avaliação. Vale ressaltar que cada anotação deve ser vinculada a uma competência exigida do avaliado.

A fase do encerramento é a fase em que as notas são atribuídas a cada uma das competências avaliadas. Ressalta-se que, antes de atribuir os conceitos para cada um dos avaliados, é importante consultar as anotações feitas sobre o seu desempenho profissional.

Dessa forma, em comparação com os métodos teóricos apresentados, a avaliação de desempenho utilizada pelo banco em estudo é condizente com a base teórica da Gestão de Desempenho por Competência (GDP), conforme apresentado na base teórica, ou seja, apresenta uma mistura da avaliação 360 graus com a avaliação balancedscorecard (BSC). Já analisando cada uma das avaliações utilizadas para compor a Gestão de Desempenho por Competência (GDP), podemos notar algumas discrepâncias entre os modelos teóricos e os aplicados pela instituição financeira.

Em relação ao sistema de avaliação de 360 graus, nota-se que a instituição financeira busca a avaliação de todos os envolvidos com o avaliado, que são internos à avaliação, não buscando a avaliação dos fornecedores ou dos clientes externos, fazendo com que a avaliação não seja completa de todos os pontos de vista.

Já em relação ao balancedscorecard (BSC), fala-se em quatro perspectivas básicas e a avaliação utilizada pela instituição financeira se aprofunda um pouco mais, utilizando, na verdade, cinco perspectivas básicas de avaliação. 
Outro ponto divergente entre os sistemas estudados e o utilizado pela empresa é a questão do feedback. Nas teorias estudadas, é dado pelos avaliadores, enquanto nessainstituição financeira, a maior parte dos avaliadores não fornece feedback, deixando que os mesmos apenas imaginem o porquê de notas baixas recebidas. Tal forma de utilização de feedback não colabora para o crescimento profissional, que é o principal objetivo do plano de Gestão de Desempenho por Competências (GDP).

\subsection{Utilização da gestão de desempenho por competência (GDP) para ascensão profissiona}

A Gestão de Desempenho por Competência (GDP) é utilizada como parte de um sistema para ascensão profissional na instituição financeira em questão. 0 sistema para ascensão utiliza a pontuação conseguida pelo funcionário em vários quesitos, sempre priorizando o colaborador que busca 0 estudo e o aperfeiçoamento.

Os quesitos somados na pontuação para ascensão profissional são conclusão de terceiro grau, pós-graduação, certificações internas de conhecimento oferecidas pela instituição financeira, cursos realizados pelo colaborador na universidade corporativa da instituição, tempo de banco, cargos exercidos na instituição e a GDP.

Para fazer parte de uma concorrência para algum cargo dentro da organização, o colaborador deve fazer sua inscrição no sistema que faz a gestão das concorrências internas da empresa e deve se classificar entre os vinte melhores concorrentes. Dessa forma, a instituição mantém seus funcionários em constante busca por capacitação para acumular pontos e poder participar de concorrências internas.

Nesse sentido, apesar de serem muitos os quesitos a serem avaliados pelo sistema de ascensão profissional, o quesito mais avaliado pelos gerentes que estão buscando um colaborador para ascensão é o da Gestão de Desempenho por Competências (GDP), pois esse índice tem a missão de traduzir como o colaborador lida com os desafios e com as metas e objetivos da organização e como procura colocar suas competências a serviço da organização.

Outro ponto importante da utilização da GDP para ascensão profissional na instituição é que os demais quesitos utilizados como forma de avaliação possuem uma pontuação máxima para cada cargo, ou seja, em algum momento não adianta mais fazer cursos ou certificações, já que a pontuação máxima foi obtida. A pontuação da GDP é dinâmica, o sistema é atualizado após todos os períodos de avaliação através de uma média das três ultimas avaliações recebidas por cada um dos funcionários. Dessa forma, a pontuação pode subir ou cair, de acordo com o desempenho apresentado durante a avaliação semestral.

Vale ressaltar que, apesar de extremamente importante na questão de ascensão profissional, a Gestão de Despenho por Competência (GDP), conforme já foi citado, não é a única questão levada em consideração. Isso se deve a tentativa da instituição de manter a imparcialidade em seu sistema de ascensão profissional, para não ficar totalmente a cargo das notas dadas por avaliadores, que, por mais que tentem manter a impessoalidade da avaliação, podem levar questões pessoais para a avaliação de desempenho.

\section{CONSIDERAÇÕES FINAIS}

Tendo em vista os aspectos apresentados durante a realização do estudo para a realização deste artigo, serão apresentadas as respostas aos objetivos apresentados, bem como a resposta à pergunta 
de pesquisa, fazendo uma conclusão geral sobre o assunto em estudo e apresentando algumas ideias para pesquisas futuras, que possam complementar a pesquisa aqui apresentada.

A pesquisa foi realizada buscando responder aos objetivos, tanto o geral quanto os específicos, e à pergunta de pesquisa, formulada no início deste trabalho.

Em relação aos objetivos, eles foram alcançados, conforme podemos verificar a seguir:

O primeiro objetivo específico tinha como meta o estudo dos modelos teóricos da Avaliação de Desempenho por Competência (GDP), buscando relacionar a teoria apresentada com a prática utilizada na instituição financeira em estudo. Esse objetivo foi alcançado ao ser feita uma descrição do modelo da Gestão de Desempenho por Competência, buscando bases teóricas para posterior utilização dessas bases na análise dos dados levantados na pesquisa documental, buscando verificar se o modelo utilizado pela instituição financeira está de acordo com os modelos teóricos estudados.

O segundo objetivo específico é realizar uma descrição do sistema de Gestão de Desempenho por Competência (GDP), utilizado na instituição bancária em estudo, que foi alcançado por meio da utilização das pesquisas documentais e da observação realizada em relação à avaliação de desempenho da instituição bancária. No estudo, foi realizada uma descrição do passo a passo para a realização da avaliação de desempenho, bem comoa forma como é realizado o desenvolvimento das competências avaliadas com notas menores do que as esperadas no processo de avaliação.

Já o terceiro objetivo específico tinha como meta explicar como a Gestão de Desempenho por Competência (GDP) é utilizada para avaliar o desempenho dos colaboradores e, em conjunto com outros fatores, é utilizada para ascensão profissional. Esse objetivo foi alcançado naanálise dos dados obtidos com pesquisas documentais e observação do processo de seleção de colaboradores nas agências que possuem vagas para promoção de funcionários. Essa observação foi realizada com relação aos principais critérios utilizados pelos gerentes para chamar os concorrentes às vagas para entrevistas, para posterior promoção. Nesse sentido, os gerentes observados levaram muito em consideração o chamado PLACAR GDP que traz o desempenho dos colaboradores, já que, conforme já citado, é um dos únicos fatores que o colaborador não consegue alterar sozinho.

Já o objetivo geral do trabalho foi alcançado na análise de como a instituição bancária usa a Gestão de Desempenho por Competência (GDP) como um dos principais fatores para ascensão profissional na empresa em estudo.

A pergunta de pesquisa "Como a Gestão de Desempenho por Competência (GDP) é utilizada em uma instituição bancária para avaliação de desempenho e consequente ascensão profissional?" foi amplamente respondida, já que os objetivos, tanto geral quanto específicos, foram respondidos. Foi realizada uma análise detalhada do sistema de Gestão de Desempenho por Competências (GDP) e de sua forma de utilização, juntamente com um conjunto de fatores, para a ascensão profissional.

Ao avaliar o sistema de avaliação de desempenho utilizada pela empresa em estudo, pode-se verificar que a instituição financeira já está bastante adiantada na utilização da avaliação de desempenho realizada semestralmente. No entanto, ainda possui vários problemas identificados pelos colaboradores avaliados, sendo que o principal deles é a escolha dos avaliadores que é conhecida por todos os participantes da avaliação de uma determinada dependência da instituição financeira, e, por isso, uma avaliação ruim acaba piorando o clima organizacional da dependência. 
Gestão de desempenho por competência (GDP): análise da avaliação de desempenho para ascensão profissional utilizada em uma instituição bancária

Vale ressaltar que esses problemas não foram focados no estudo apresentado, por não serem necessários para a resolução dos objetivos. No entanto, não devemos imaginar que o sistema utilizado pela instituição financeira é isento de falhas.

Outra questão importante é que o sistema atualmente utilizado não busca a realização de feedback entre os avaliadores e os avaliados. Os envolvidos verificam suas notas no sistema, entretanto, não é realizada uma reunião com os avaliadores para discutir os pontos que foram considerados abaixo do padrão esperado pelo banco para dinamizar o crescimento profissional do avaliado.

Outro ponto a considerar é que, devido ao trabalho corrido do dia a dia, realizar anotações no sistema para cada um dos pontos que devem ser melhorados pelo avaliado se torna bastante difícil, o que faz com que, muitas vezes, devido à falta de tempo, o avaliado não receba notas realmente baixas do avaliador, notas essas que não podem ser dadas sem anotações no sistema da GDP, o que gera uma nota falsamente positiva para o avaliado que acredita que está desempenhando bem suas funções, mas, na realidade, precisaria realizar algumas ações para melhoria de seu desempenho profissional.

Vale ressaltar que, apesar de todas essas questões apresentadas, a empresa está buscando uma melhoria constante na sua avaliação de desempenho e já a utiliza para ascensão profissional, o que a torna um caso a ser estudado para empresas que ainda estão implementando seus programas de avaliação. Sabe-se que, em inúmeras empresas, a avaliação de desempenho até existe, mas não é utilizada de forma estruturada, sendo que a maior parte dos funcionários não conhece seus resultados ou a forma como os mesmos serão utilizados dentro da organização, gerando, dessa maneira, mais dúvidas do que satisfação profissional nos colaboradores.

As principais limitações encontradas na realização deste estudo foram:

- Falta de material para pesquisa documental na instituição financeira em estudo;

- Informações sobre o sistema de Gestão de Desempenho por Competência (GDP) passados de forma informal para os novos colaboradores da empresa, não existindo uma padronização da forma;

- Impossibilidade de contato com os responsáveis pela programação do sistema de Gestão de Desempenho por Competência (GDP) para tirar dúvidas sobre a utilização do sistema;

- Falta de material de apoio bibliográfico sobre a Gestão de Desempenho por Competência (GDP) tanto em livros, quanto em artigos e sites da internet.

Algumas novas pesquisas podem ser realizadas para complementar o estudo apresentado, como, por exemplo:

- Como a instituição financeira faz para diminuir a subjetividade do processo de avaliação;

- Forma de escolha dos avaliadores para cada um dos avaliados e como isso pode influenciar nos resultados da avaliação de desempenho;

- Implantação de um sistema em que o avaliado tenha a possibilidade de responder ao avaliador sobre seu resultado, em caso de discordar dos conceitos atribuídos e as consequências dessa implantação para a avaliação de desempenho. 


\section{REFERÊNCIAS}

ALMEIDA, Rosana da Costa de. Avaliação de desempenho: Gestão de desempenho por competências (GDP) do Banco do Brasil. Rio de Janeiro: Universidade Candido Mendes, 2007. Disponível em <http:// www.avm.edu.br/monopdf/9/ROSANE\%20COSTA\%20DE\%20ALMEIDA.pdf>Acesso em 17 set. 2014.

ARAUJO, Luis César G. de. Gestão de pessoas: estratégias e integração organizacional. São Paulo: Atlas, 2006.

BELFORD, Rhecyelle Mota; SANTOS, Edianadi Franco Matos da Silva; TADEUCCI, Marilsa de Sá Rodrigues. Gestão por competências: um novo modelo de gerenciamento. Revista UNI, Imperatriz (MA), ano 2, n.2, p. 39-53, janeiro/julho, 2012.

BRANDÃO, H. P.; GUIMARÃES, T. A. Gestão de competências e gestão de desempenho: tecnologias distintas ou instrumentos de um mesmo construto? RAE: Revista de Administração de Empresas, São Paulo, v. 41, n. 1, p.8-15, jan./mar. 2001

CHIAVENATO, Idalberto. Gestão depessoas. Rio de Janeiro: Elsevier, 2004

CHIAVENATO, Idalberto. Administração geral e pública. Série provas e concursos. Rio de Janeiro: Elsevier, 2006

DURAND, T. Forms of incompetence. In: INTERNATIONL CONFERENCE ON COMPETENCE-BASED MANAGEMENT, 4., 1998, Oslo. Proceedings... Oslo: NorwegianSchoolof Management, 1998.

DUTRA, Celia. Tendências na Gestão de Pessoas. Disponivel em <http://www.ecrconsultoria.com.br/ biblioteca/artigos/gestao-de-pessoas/tendencias-na-gestao-de-pessoas>. Acesso em 10 set. 2014.

GIL, Antonio Carlos. Como elaborar projetos de pesquisa. 5. ed. São Paulo: Atlas, 2008.

G.T.H Consultoria em RH. Avaliação de desempenho por incidentes críticos. Disponível em <http:// gthconsultoria.blogspot.com.br/2011/09/avaliacao-de-desempenho-por-incidentes.html>. Acesso em 29 set. 2014.

LEOPARDI, M.T. Metodologia da pesquisa na saúde. Santa Maria: Pallotti, 2001.

LUCIA, Maria. Avaliação de Desempenho: Uma estratégia para o crescimento. Disponível em <http:// assessoriaconrado.blogspot.com.br/2011/10/avaliacao-de-desempenho-uma-estrategia.html>. Acesso em 29 set. 2014.

RIBAS, Andréia; SALIN, Cassiano. As avaliações de desempenho: Escala Gráfica. Disponível em < $\underline{\text { http:// }}$ gpparaconcursos.blogspot.com.br/2012/12/as-avaliacoes-de-desempenho-escala.html>. Acesso em 29 set. 2014.

RIBEIRO, Antonio de Lima. Gestão de Pessoas. São Paulo: Saraiva, 2006.

RICHARDSON, Roberto Jarry. Pesquisa social: métodos e técnicas. 3.ed. São Paulo: Atlas, 1999. 
Gestão de desempenho por competência (GDP): análise da avaliação de desempenho para ascensão profissional utilizada em uma instituição bancária

MENDES, Ricardo. O que é gestão de competências. Disponível em <http://www.gestaoporcompetencias. com.br/artigo-recursos-humanos/artigo-rh/o_que_e_gestao_por_competencias/>. Acesso em 11 set. 2014.

MORAES, Roque. Análise de conteúdo. Revista Educação, Porto Alegre, v. 22, n. 37, p. 7-32, 1999, disponível $\mathrm{em}<\mathrm{http}$ ://cliente.argo.com.br/ mgos/analise_de_conteudo_moraes.html >. Acesso em 11 ago. 2014.

PERIARD, Gustavo. Avaliação $\mathbf{3 6 0}$ graus - o que é e como funciona. Disponível em <http://www. sobreadministracao.com/avaliacao-360-graus-o-que-e-e-como-funciona/>. Acesso em 01 out. 2014.

PINTO, Sandra Regina da Rocha (coordenadora); PEREIRA, Claudio de Souza; COUTINHO, Maria Teresa Correia; JOHANN, Silvio Luiz. Dimensões funcionais da gestão de pessoas. Rio de Janeiro: Editora FGV, 2003.

T.R.T - MG, Gestão estratégica. Metodologia Balanced Scorecard (BSC). Disponível emhttps://www.trt3. jus.br/gestaoestrategica/planejamento/metodologia/metodologia_bsc.htm . Acesso em 01 out. 2014. 